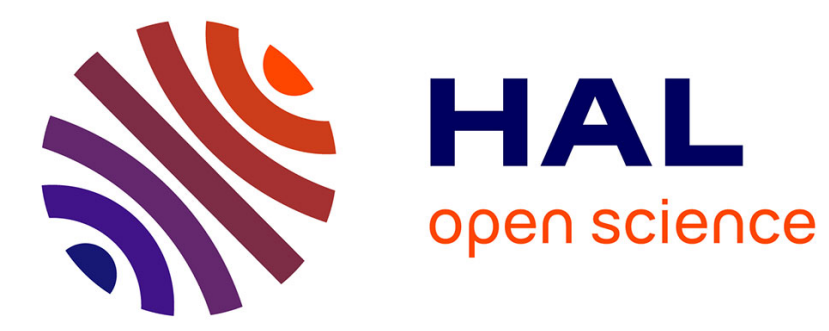

\title{
Impact of the Hajj on pneumococcal carriage and the effect of various pneumococcal vaccines
}

Sophie Edouard, Jaffar A. Al-Tawfiq, Ziad A. Memish, Saber Yezli, Philippe

Gautret

\section{- To cite this version:}

Sophie Edouard, Jaffar A. Al-Tawfiq, Ziad A. Memish, Saber Yezli, Philippe Gautret. Impact of the Hajj on pneumococcal carriage and the effect of various pneumococcal vaccines. Vaccine, 2018, 36 (48), pp.7415-7422. 10.1016/j.vaccine.2018.09.017 . hal-01970227

\section{HAL Id: hal-01970227 \\ https://hal.science/hal-01970227}

Submitted on 11 Apr 2019

HAL is a multi-disciplinary open access archive for the deposit and dissemination of scientific research documents, whether they are published or not. The documents may come from teaching and research institutions in France or abroad, or from public or private research centers.
L'archive ouverte pluridisciplinaire HAL, est destinée au dépôt et à la diffusion de documents scientifiques de niveau recherche, publiés ou non, émanant des établissements d'enseignement et de recherche français ou étrangers, des laboratoires publics ou privés. 


\title{
Impact of the Hajj on pneumococcal carriage and the effect of various pneumococcal vaccines
}

\author{
Sophie Edouard ${ }^{a}$, Jaffar A. Al-Tawfiq ${ }^{\text {b,c }}$, Ziad A. Memish ${ }^{\mathrm{d}}$, Saber Yezli ${ }^{\mathrm{e}}$, Philippe Gautret ${ }^{\mathrm{f}, *}$ \\ a Aix Marseille Univ, IRD, APHM, MEPHI, IHU-Méditerranée Infection, Marseille, France \\ ${ }^{\mathrm{b}}$ Specialty Internal Medicine Unit, Johns Hopkins Aramco Healthcare, Dhahran, Saudi Arabia \\ ${ }^{\mathrm{c}}$ Indiana University School of Medicine, Indianapolis, IN 46202, USA \\ ${ }^{\mathrm{d}}$ Ministry of Health and College of Medicine, Alfaisal University, Riyadh, Saudi Arabia \\ e The Global Centre for Mass Gatherings Medicine, Ministry of Health, Riyadh, Saudi Arabia \\ ${ }^{\mathrm{f}}$ Aix Marseille Univ, IRD, AP-HM, SSA, VITROME, IHU-Méditerranée Infection, Marseille, France
}

\section{A R T I C L E I N F O}

\section{Article history:}

Received 4 April 2018

Received in revised form 13 August 2018

Accepted 10 September 2018

Available online 17 September 2018

\section{Keywords:}

S. pneumoniae

Carriage

Pilgrim

Hajj

qPCR

Vaccine

\begin{abstract}
A B S T R A C T
Background: The Islamic Hajj pilgrimage is the largest annual mass gathering in the world. The overcrowding of people promotes the acquisition, spread and transmission of respiratory pathogens, including Streptococcus pneumoniae.

Methods: We conducted a methodological review according to the Preferred Reporting Items for Systematic Reviews and Meta-Analysis guidelines. The objective was to summarize the available data regarding the prevalence of pneumococcal carriage among Hajj pilgrims and about carriage acquisition and circulation of S. pneumoniae among pilgrims before and after participating in the Hajj according to their vaccination status.

Results: Eight articles met eligibility criteria for pneumococcal carriage and impact of pneumococcal vaccination on carriage. Seven of them showed a significant increase in nasopharyngeal carriage of pneumococci following the pilgrimage, with acquisition rates ranging from 18 to $36 \%$. Serotypes $3,19 \mathrm{~F}$ and 34 are the most common. A significant increase in antibiotic resistant strains was observed following participation in the Hajj. A lower prevalence was found in pilgrims treated with antibiotics, those who used a hand sanitizer, or those who washed their hands more frequently than usual. An increased carriage of pneumococcal serotypes included in pneumococcal vaccines (10-valent pneumococcal conjugate vaccine (PCV10), 13-valent pneumococcal conjugate vaccine (PCV13), 23-valent pneumococcal polysaccharide vaccine (PPV23)) was observed following participation in the Hajj. To date, no study has shown a significant reduction in pneumococcal carriage among pilgrims after vaccination with PPV23 or PCV. In fact, no significant difference was currently observed in the prevalence ratio of pneumococcal carriage between vaccinated and unvaccinated pilgrims.

Conclusion: The studies analyzed in this review showed an increased carriage of pneumococcus in postHajj pilgrims compared to pre-Hajj pilgrims, including vaccine serotypes. Further studies are needed to investigate the possible relationships between carriage, disease and vaccine in pilgrims.
\end{abstract}

(c) 2018 Elsevier Ltd. All rights reserved.

\section{Introduction}

The Hajj is the largest annual mass gathering in the world. The Islamic pilgrimage to Mecca in Saudi Arabia attracts 2-3 million pilgrims from more than 180 countries [1]. The overcrowding of people promotes the acquisition, spread and transmission of pathogenic micro-organisms. Respiratory diseases are the most

* Corresponding author at: Institut Hospitalo-Universitaire Méditerranée Infection, 19-21 Boulevard Jean Moulin, 13385 Marseille Cedex 05, France.

E-mail address: philippe.gautret@club-internet.fr (P. Gautret). common infections during the pilgrimage. Community-acquired pneumonia (CAP) is a leading cause of hospitalization and the primary cause of critical illness among pilgrims [2-4]. Pneumonia occurs preferentially in the second week, between days 5-15 coinciding with the actual pilgrimage, when the pilgrim density is maximal [5]. A more recent study showed that most cases of CAP related to the Hajj, whom $71 \%$ required hospitalization, occur the week after the pilgrimage, just after the peak, corresponding to the incubation time after the acquisition of the bacteria before the onset of symptoms [3]. The etiology of respiratory tract infection is complex, and a wide variety of bacteria and viruses 
are associated with respiratory disorders, with Streptococcus pneumoniae being one of the most common pathogens isolated from patients [5]. The prevalence of CAP attributable to S. pneumoniae among pilgrims was evaluated to $18 \%$ based on culture and urinary antigen detection test [3].

There are more than 90 different serotypes of S. pneumoniae [6], and their distribution varies by age, geographical area and clinical syndrome. Pneumococcal acquisition and subsequent nasopharyngeal carriage are considered the main source of pneumococcal horizontal transmission between persons, and a precursor for pneumococcal diseases. The natural route of pneumococcal infection is initiated by nasopharyngeal colonization with the homologous strain, and may progress to invasive disease especially if natural immunological barriers are crossed [7]. The nasopharyngeal colonization is an important key to the occurrence of pneumococcal disease including bacteriemic and non bacteriemic CAP, invasive pneumococcal infection (IPD) but also for its prevention [7]. Several host and environmental factors influence pneumococcal carriage including age, immune status, antibiotic consumption, pneumococcal vaccination, seasons or geographical area $[7,8]$ Cremers et al. showed that nasopharyngeal microbiota could also influence pneumococcal acquisition [8].

Moreover, a significant number of asymptomatic carriers of $S$. pneumoniae was observed $[7,9,10]$. Children aged less than 5 years constitute the most significant reservoir of $S$. pneumoniae. The rate of pneumococcal carriage observed in young children can reach $60 \%$, including after vaccine implementation [10], and coincides with the highest incidence of IPD among children [11]. S. pneumoniae carriage rate decreases to approximately $10-20 \%$ in adults, and paradoxically, despite the high prevalence of IPD and CAP in elderly people, a lower asymptomatic carriage rate (5-22\%) is observed in this population [9,11,12]. Indeed, among elderly people, the risk of IPD is related to underlying medical and/or socio-demographic conditions and less clearly to the frequency of carriage [11]. The Hajj pilgrim population is characterized by a significant proportion of individuals aged $>65$ years with chronic medical conditions, including diabetes mellitus, cardiovascular disorders, asthma, immune deficiency and chronic respiratory disease, placing them at frequent risk for IPD [13]. It is estimated that about $33 \%$ of Hajj pilgrims are at risk of pneumococcal disease due to age or presence of underlying comorbidities [14]. Furthermore, crowding conditions experienced by pilgrims favor the transmission of respiratory pathogens [15]. The acquisition of carriage of potentially pathogenic respiratory microbes is very frequent during the Hajj and is well demonstrated for viruses [16]. However, there are fewer studies addressing bacterial acquisition. Characterizing the carriage of pneumococcus and assessing the impact of vaccination in pilgrims can offer relevant information about their risk for IPD.

The objective of this review is to summarize available data about the prevalence of $S$. pneumoniae carriage among Hajj pilgrims, as well as data about carriage acquisition and circulation of $S$. pneumoniae among pilgrims before and after participating in the Hajj, according to their vaccination status.

\section{Methods}

\subsection{Search strategy and selection criteria}

The systematic review was conducted according to the Preferred Reporting Items for Systematic Reviews and Meta-Analysis (PRISMA) guidelines (http://www.prismastatement.org). The following databases were searched, attempting to identify all relevant studies published from January 1980 to February 2018: Scopus (http://www.scopus.com/) and PubMed (http://www.ncbi.nlm. nih.gov/pubmed). The latest search was conducted on February 28,2018 . The topic search terms used for searching the databases were as follows: \#1: "hadj" OR "hajj" OR "pilgrimage"; \#2: "Streptococcus pneumoniae" OR "Pneumococcus"; \#3: "\#1 AND \#2". Only articles published in English were included, based on the common language shared by the authors. For inclusion the article needed to fulfill the following criteria: [i] it needed to be related to the Hajj pilgrimage; [ii] report on screening in asymptomatic or symptomatic participants; [iii] present bacteriological data and; [iv] report on S. pneumoniae carriage prevalence. Reporting on vaccination status was used as an optional criterion. We excluded case reports and studies conducted among ill pilgrims in the hospital and outpatient setting because our paper focuses only on S. pneumoniae carriage" The reference lists of reviews were screened to identify studies possibly missed by the search. Two researchers (S.E. and P.G.) independently performed the screening of the abstracts. Any discordant result was discussed in consensus meetings. After screening the abstracts, the full text of the articles was assessed for eligibility by the same two researchers and selected or rejected for inclusion in the systematic review.

\subsection{Data collection process}

The following data (if available) were extracted from each article: year of the study, study design, study population, type of sample taken, microbiological methods used, pathogen prevalence, pneumococcal vaccination rates and their effect on S. pneumoniae carriage prevalence.

\subsection{Data synthesis and analysis}

The study results were summarized to describe the main outcomes of interest (i.e., the prevalence of $S$. pneumoniae before and/or after participation in the Hajj).

To evaluate the effect of pneumococcal vaccine, the dichotomous data on the number of subjects with $S$. pneumoniae carriage post-Hajj in the vaccinated group and unvaccinated control group were extracted from each study with subsequent determination of the odd ratios (OR) and their 95\% confidence intervals (CI). We combined data statistically using random effects (MantelHaenszel method) model due the differences in among the studies. $\mathrm{Chi}^{2}$ and $I^{2}$ statistics were used to assess the heterogeneity among the included studies. Values of $I^{2}$ can be interpreted as low (25-50\%), moderate (50-75\%), and high (75\% and greater) levels of heterogeneity. Meta-analyses were performed using Review Manager (RevMan 5.3, Cochrane Collaboration). Results were considered to be statistically significant with a $\mathrm{p}$ value of $<0.05$.

\section{Results}

\subsection{Study selection}

A total of 55 articles were selected from the search, and no additional reference was found through a manual search. After screening of titles and abstracts, eight articles were selected for full-text assessment [17-21]. All eight articles were included in the qualitative synthesis of the systematic review (Fig. 1).

\subsection{Prevalence and acquisition of S. pneumoniae carriage in pilgrims}

To date, eight studies reported the prevalence of nasopharyngeal carriage of $S$. pneumoniae among Hajj pilgrims (Table 1 and Fig. 2). Most of the studies used specific qPCR for $S$. pneumoniae detection [19-21], two used only a bacterial culture approach $[17,18]$ and one study used both qPCR and culture with a 


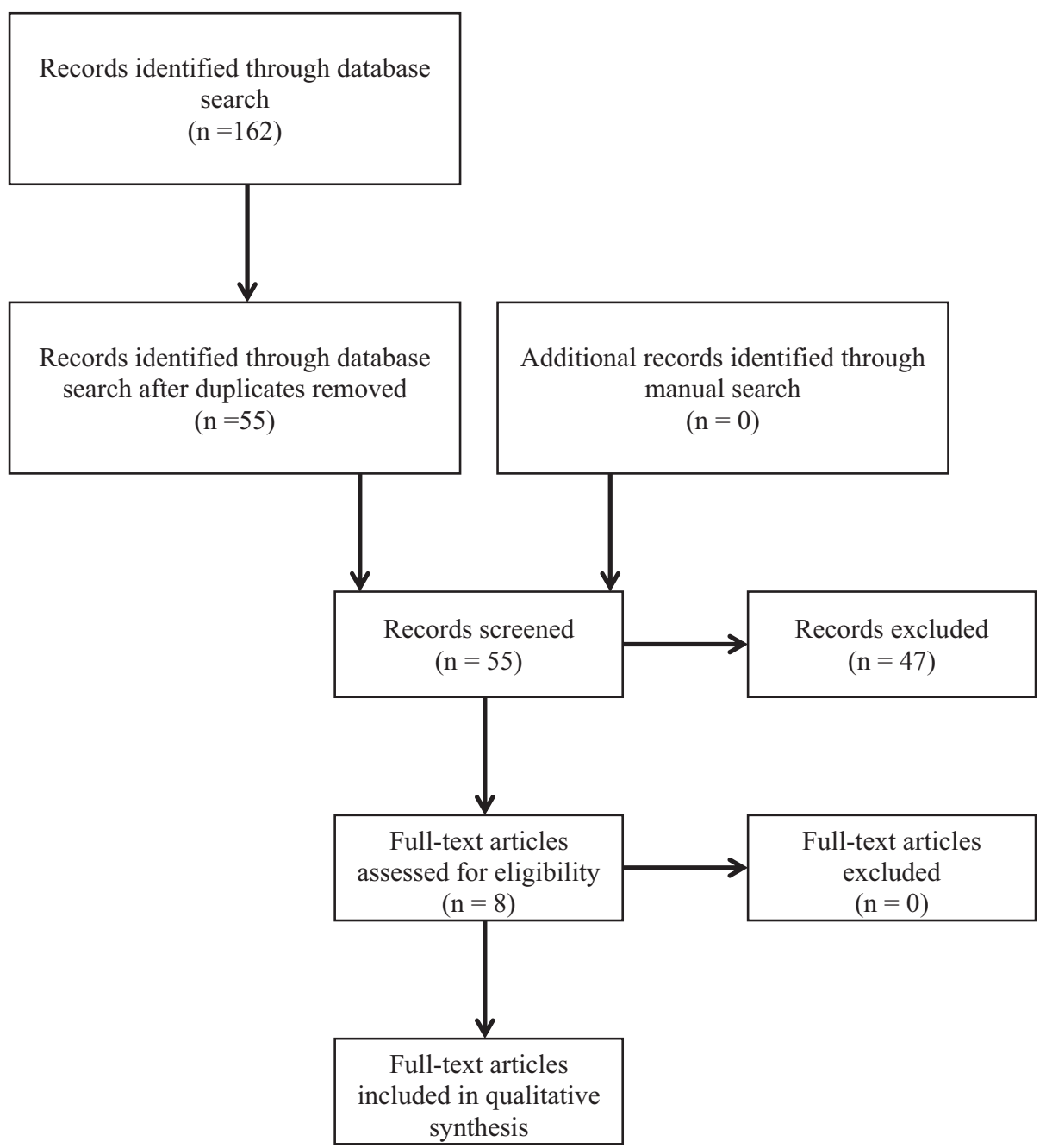

Fig. 1. Search strategy flow diagram.

comparative approach [22]. Two studies were elaborated by the same team that proposed prospective longitudinal studies in cohorts of French pilgrims to investigate the nasopharyngeal carriage of $S$. pneumoniae $[19,20]$. The nasopharyngeal samples were collected before the departure from France, during the pilgrimage only in symptomatic people presenting acute respiratory signs, and at the end of the pilgrimage for 2 consecutive years [19,20]. Benkouiten et al., reported the first work describing $S$. pneumoniae nasal carriage in 169 pilgrims during the Hajj season of 2012 [20]. They reported a significant increase in $S$. pneumoniae prevalence between pre-Hajj samples and post-Hajj samples (7.3\% versus $19.5 \%, \mathrm{p}=0.0001)$. The prevalence of $S$. pneumoniae among the 70 symptomatic pilgrims additionally sampled during the pilgrimage was $7.1 \%$. A lower prevalence was found in pilgrims treated with antibiotics compared to other pilgrims (17\% versus $25.5 \%$, respectively, $\mathrm{p}=0.224$ ) but this difference was not significant [20]. The subsequent study during the 2013 Hajj included 129 French pilgrims in whom a throat specimen was collected pre- and postHajj. The carriage of S. pneumoniae was estimated at $50 \%$ in preHajj and $62 \%$ in post-Hajj specimens $(p=0.053)$ and was significantly higher than the previous years [19]. Nasal acquisition of S. pneumoniae was reported in $18.2 \%$ of pilgrims sampled in the 2012 Hajj, while 36.3\% pharyngeal acquisition was demonstrated during the 2013 Hajj, suggesting important inter-individual transmission of the bacteria in an overcrowding context. The prevalence of the bacteria was lower in patients using hand sanitizer (55.2\% versus $76.2 \%, \mathrm{p}=0.021)$ and in those performing frequent hand washing (54.7\% versus 69.2\%, p = 0.08) [19]. Among the 63 subjects with positive qPCR for pneumococcus before departure for the 2013 Hajj, 12 (19\%) were negative at the end of the pilgrimage with 10 out of 12 having receive antibiotic treatment during their stay [19], supporting the data showing a lower prevalence of nasopharyngeal carriage after antibiotic therapy.

Memish et al. conducted a larger scale carriage study enrolling 3203 pilgrims originating from Asia and Africa during the 2011 and 2012 Hajj [17]. A nasopharyngeal sample was collected pre- and post-Hajj and culture techniques were used to identify the carriage organisms. They found a significant increase in carriage of $S$. pneumoniae ( $4.4 \%$ versus $7.5 \%, \mathrm{p}=0.0002$ ), a significant increase in at least one antibiotic non-susceptible strain $(2.5 \%$ versus $6.1 \%$, $\mathrm{p}<0.0001)$ and a significant increase in multiple antibiotic nonsusceptible strains $(0.6 \%$ versus $2.2 \%, \mathrm{p}<0.0001)$ between preHajj and post-Hajj cohorts. Fifty-two serotypes were identified, with serotypes 3 (17\%), 19F (5\%) and 34 (5\%) being the most common. The cross sectional design of the study based on non-paired cohorts did not allow calculation of acquisition rates. A paired cohort culture-based study including 1175 pilgrims from various origin was conducted during the $2013 \mathrm{Hajj}$ and showed an increase in S. pneumoniae carriage from $1.8 \%$ pre-Hajj to $7.1 \%$ post-Hajj $(p=0.0016)$ [18]. Serotype 3 was also the most common (9.1\%), followed by serotypes 6A (7.3\%), 19F (6.4\%), 23F (5.5\%) and 34 (5.5\%). Another carriage study was performed during the $2013 \mathrm{Hajj}$, when 
Table 1

Study characteristics and prevalence of Streptococcus pneumoniae carriage in Hajj pilgrims.

\begin{tabular}{|c|c|c|c|c|c|c|c|c|}
\hline Study & $\begin{array}{l}\text { Hajj } \\
\text { seasons }\end{array}$ & Study design & Subjects & Type of sample & $\begin{array}{l}\text { Detection } \\
\text { tools }\end{array}$ & $\begin{array}{l}\text { Vaccination rate } \\
\text { against invasive } \\
\text { pneumococcal disease }\end{array}$ & $\begin{array}{l}\text { Prevalence of } \\
\text { Streptococcus } \\
\text { pneumoniae }\end{array}$ & References \\
\hline 1 & $\begin{array}{l}2011- \\
2012\end{array}$ & $\begin{array}{l}\text { Non-paired } \\
\text { cross-sectional } \\
\text { cohort survey }\end{array}$ & $\begin{array}{l}1590 \text { pre-Hajj and } 1613 \text { post-Hajj } \\
\text { pilgrims from } 18 \text { countries in Africa } \\
\text { and Asia }\end{array}$ & $\begin{array}{l}\text { Nasopharyngeal } \\
\text { swab }\end{array}$ & Culture & $\begin{array}{l}\text { 11.3\% (type of vaccine } \\
\text { not documented) }\end{array}$ & $\begin{array}{l}4.4 \% \text { pre-Hajj/ } \\
7.5 \% \text { post-Hajj }\end{array}$ & [17] \\
\hline 2 & 2012 & $\begin{array}{l}\text { Paired } \\
\text { prospective } \\
\text { cohort survey }\end{array}$ & 169 French pilgrims & $\begin{array}{l}\text { Nasal swab } \\
\text { (anterior nares) }\end{array}$ & qPCR & $\begin{array}{l}35.9 \% \text { (polysaccharide } \\
\text { vaccine) }\end{array}$ & $\begin{array}{l}\text { 7.3\% pre-Hajj/ } \\
\text { 19.5\% post-Hajj }\end{array}$ & {$[20]$} \\
\hline 3 & 2013 & $\begin{array}{l}\text { Paired } \\
\text { prospective } \\
\text { cohort survey }\end{array}$ & 129 French pilgrims & $\begin{array}{l}\text { Oropharyngeal } \\
\text { swab (throat) }\end{array}$ & qPCR & $\begin{array}{l}51.2 \% \text { (polysaccharide } \\
\text { vaccine) }\end{array}$ & $\begin{array}{l}50.0 \% \text { pre-Hajj/ } \\
62.0 \% \text { post-Hajj }\end{array}$ & [19] \\
\hline 4 & 2013 & $\begin{array}{l}\text { Paired } \\
\text { prospective } \\
\text { cohort survey }\end{array}$ & $\begin{array}{l}692 \text { pilgrims from } 11 \text { countries in } \\
\text { Africa, Asia, Europe and US }\end{array}$ & $\begin{array}{l}\text { Nasopharyngeal } \\
\text { swab }\end{array}$ & qPCR & $\begin{array}{l}1.9 \% \text { (type of vaccine } \\
\text { not documented) }\end{array}$ & $\begin{array}{l}5.6 \% \text { pre-Hajj/ } \\
12.7 \% \text { post-Hajj }\end{array}$ & {$[21]$} \\
\hline 5 & 2013 & $\begin{array}{l}\text { Non-paired } \\
\text { cross-sectional } \\
\text { cohort survey }\end{array}$ & $\begin{array}{l}514 \text { pre-Hajj and } 470 \text { post-Hajj } \\
\text { pilgrims from } 13 \text { countries in Africa, } \\
\text { Asia, Europe and US }\end{array}$ & $\begin{array}{l}\text { Nasal swab } \\
\text { (anterior nares) }\end{array}$ & qPCR & $\begin{array}{l}0.2 \% \text { (type of vaccine } \\
\text { not documented) }\end{array}$ & $\begin{array}{l}4.7 \% \text { pre-Hajj/ } \\
13.6 \% \text { post-Hajj }\end{array}$ & {$[21]$} \\
\hline 6. & 2013 & $\begin{array}{l}\text { Paired } \\
\text { prospective } \\
\text { cohort survey }\end{array}$ & 1175 pilgrims (multinational) & $\begin{array}{l}\text { Nasopharyngeal } \\
\text { swab }\end{array}$ & Culture & $\begin{array}{l}1.4 \% \text { (conjugate } \\
\text { vaccine PCV7) }\end{array}$ & $\begin{array}{l}1.8 \% \text { pre-Hajj/ } \\
7.1 \% \text { post/Hajj }\end{array}$ & [18] \\
\hline 7. & 2013 & $\begin{array}{l}\text { Cross-sectional } \\
\text { cohort survey }\end{array}$ & $\begin{array}{l}551 \text { post-Hajj pilgrims from } \\
\text { Malaysia }\end{array}$ & $\begin{array}{l}\text { Sputum and } \\
\text { oropharyngeal } \\
\text { swab }\end{array}$ & Culture & $\begin{array}{l}\text { 79.3\% (type of vaccine } \\
\text { not documented) }\end{array}$ & $1.81 \%$ post-Hajj & [23] \\
\hline 8. & 2014 & $\begin{array}{l}\text { Non-paired } \\
\text { cross-sectional } \\
\text { cohort survey }\end{array}$ & $\begin{array}{l}183 \text { during-Hajj and } 93 \text { post Hajj } \\
\text { pilgrims from Australia }\end{array}$ & $\begin{array}{l}\text { Nasopharyngeal } \\
\text { or } \\
\text { oropharyngeal } \\
\text { swab }\end{array}$ & $\begin{array}{l}\text { During } \\
\text { Hajj } \\
\text { (qPCR) } \\
\text { Post Hajj } \\
\text { (Culture) }\end{array}$ & $\begin{array}{l}27.5 \% \text { (conjugate } \\
\text { vaccine PCV13) }\end{array}$ & $\begin{array}{l}14.2 \% \text { during } \\
\text { Hajj/1.1\% post } \\
\text { Hajj }\end{array}$ & [24] \\
\hline 9. & 2016 & $\begin{array}{l}\text { Paired } \\
\text { prospective } \\
\text { cohort survey }\end{array}$ & 807 Indian pilgrims & $\begin{array}{l}\text { Oropharyngeal } \\
\text { swab and nasal } \\
\text { swab }\end{array}$ & $\begin{array}{l}\text { qPCR and } \\
\text { culture }\end{array}$ & $0 \%$ & $\begin{array}{l}\text { 19\% pre- Hajj/ } \\
21.8 \% \text { post Hajj } \\
6.5 \% \text { pre-Hajj/ } \\
8.2 \% \text { post Hajj }\end{array}$ & {$[22]$} \\
\hline
\end{tabular}

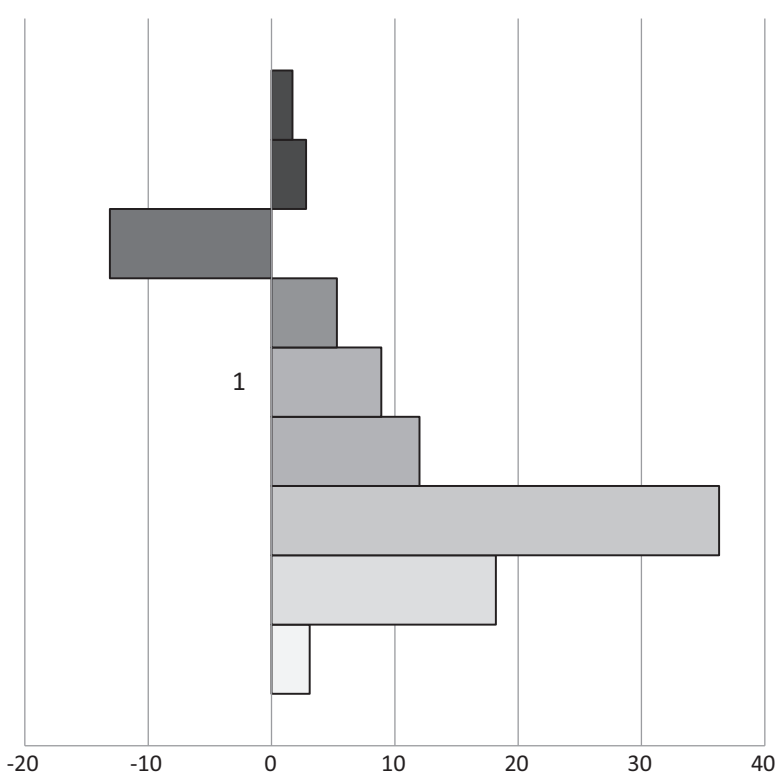

Ganaie, $2018[22]$ culture*

Ganaie, 2018 [22] qPCR*

Azeem, $2017[24]^{*}$

Memish, $2016[18]^{*}$

Memish, 2015 [21] unpaired cohort*

$\square$ Memish, 2015 [21] paired cohort**

Benkouiten, 2014 [19]**

Benkouiten, 2014 [20]**

Memish, 2015 [17]*

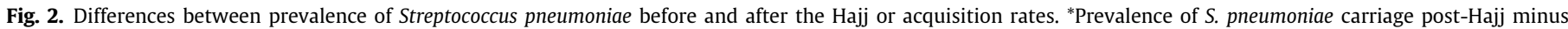
prevalence of S. pneumoniae carriage pre-Hajj, ${ }^{* *}$ acquisition rate (proportion of pilgrims positive for S. pneumoniae post Hajj and negative pre-Hajj).

pilgrims from 13 different countries in Asia, Africa and Europe and the United States were enrolled and tested by qPCR [21]. Two cohorts (one paired and one non-paired) were followed. The prevalence of S. pneumoniae increased significantly among pre-Hajj nasal specimens (5.6\%) compared to post-Hajj nasal specimens (12.7\%) $(\mathrm{p}<0.001)$ in the paired cohort $(\mathrm{n}=632)$. A significant difference was also observed in the non-paired cohort $(n=514$ arriving and $\mathrm{n}=470$ departing pilgrims), $4.7 \%$ versus $13.6 \%(\mathrm{p}<0.001)$. A
$1.81 \%$ pharyngeal carriage of $S$. pneumoniae was described in 551 Malaysian pilgrim returning from Hajj 2013 using culture; preHajj data were not collected [23]. In 2014, pneumococcal carriage was evaluated to $14.2 \%$ using qPCR in pilgrims from Australia at the fifth days of the pilgrimage and decrease to $1.1 \%$ in pilgrims sampled two months after the pilgrimage [24]. However, only $30 / 246$ pilgrims were paired in the 2 phases of their study and the diagnostic test used for the samples collected during and after 
the Hajj differed. They used qPCR to test the sample collected at the fifth days and then culture to test the sample collected after the pilgrimage, respectively. More recently, nasopharyngeal carriage of S. pneumoniae was evaluated during the Hajj 2016 in 807 Indian pilgrims at $19 \%$ before the pilgrimage and $21.8 \%$ after the pilgrimage using $\mathrm{qPCR}(\mathrm{p}=0.048)$ and to $6.5 \%$ and $8.2 \%$ using culture $(\mathrm{p}=0.064)$. Multidrug resistant pneumococcus carriage also increased from $11 \%$ in the pre-Hajj pilgrims to $32 \%$ in the postHajj pilgrims $(p=0.0002)$. Thirty-two different serotypes were identified, with serotypes $19 \mathrm{~F}$ (20\%), $9 \mathrm{~V}$ (7.2\%) and 1 (6.2\%) being the most common during the Hajj. Multiple serotypes were found in $12 \%$ of the pilgrims [22].

\subsection{Effect of vaccination on pneumococcal carriage at the Hajj}

\subsubsection{Vaccine coverage against S. pneumoniae}

Currently, two types of vaccines against S. pneumoniae are available, including the 23-valent pneumococcal polysaccharide vaccine (PPSV23) and the 10 and 13-valent pneumococcal conjugate vaccine PCV10 and PCV13. The first pneumococcal conjugate vaccine PCV7 was licensed in 2000 and replaced by PCV13 in 2010 [25]. Few studies report the proportion of vaccinated people among pilgrims. This prevalence is variable according to the country of origin of pilgrims, but is globally low, even in at-risk individuals (Table 2). The proportion of those vaccinated has tended to increase in recent years, but still remains very low in some countries [26]. In French pilgrims, 31.4\% were vaccinated in 2009 versus $51.2 \%$ in 2013 [19], while in Australian pilgrims, 28.5\% were vaccinated in 2011 versus $14.2 \%$ in 2013 [27]. The vaccination rate in multinational cohorts varied from $0.2 \%$ [21] to $11.3 \%$ [17]. The lower vaccination rate $(0 \%)$ was reported in India during the Hajj 2016 [22] and the higher vaccination rate was reported in a Malaysian cohort during Hajj 2013 with 79.9\% of vaccinated pilgrims [23].

\subsubsection{S. pneumoniae carriage according to vaccination status}

To date, only one study has shown a significant reduction in pneumococcal carriage after vaccination among pilgrims. In the multinational cohort of the 2011 and 2012 Hajj, the rate of postHajj pneumococcal carriage was higher in vaccinated pilgrims compared to unvaccinated pilgrims, although the difference was not statistically significant (10.0\% versus $6.5 \%$, respectively) [17].
Moreover, the prevalence ratio of pneumococcal carriage between pre-Hajj and post-Hajj samples was higher in the vaccinated group compared to the unvaccinated group (3.4 versus 1.3 ) [17]. In the 2012 French pilgrim cohort, 19.1\% of the PPV23-vaccinated pilgrims were positive for S. pneumoniae at the end of the Hajj, compared to $19.6 \%$ in unvaccinated pilgrims [20]. The year after, during the 2013 Hajj, 56.1\% of the PPV23-vaccinated French pilgrims were positive for S. pneumoniae at the end of the Hajj, compared to $68.3 \%$ in the control group [19]. In the Australian cohort, the carriage of $S$. pneumoniae was $10.5 \%$ in PCV13-vaccinated pilgrims versus $15.2 \%$ in unvaccinated pilgrims during the Hajj 2014, a difference which was not significant; post-Hajj S. pneumoniae carriage was nil in the vaccinated group and $1.8 \%$ in controls17] [24]. However, Ismail et al. are the only to report a significant reduction of $S$. pneumoniae acquisition in vaccinated Malaysian pilgrims (5/388, 1.3\%) compared to unvaccinated pilgrims [(5/100,5\%), $(\mathrm{p}=0.03)][23]$.

The results of the meta-analysis showed that the pooled ORs did not reach statistical significance with $\mathrm{p}=0.48$ and a high level of heterogeneity was observed between studies $\left(I^{2}=64 \%\right)$ (Fig. 3 ).

\subsubsection{Prevalence of vaccine serotype}

Two studies reported a higher carriage of the vaccine pneumococcal serotype in post-Hajj pilgrims compared to pre-Hajj pilgrims [17,18]. Among the 3203 subjects enrolled during the 2011 and 2012 Hajj, Memish et al. observed a higher carriage of the pneumococcal serotype present in the PCV13 vaccine in the postHajj specimen compared to pre-Hajj specimens (1.1\% versus 3.6\%; PR 3.2, 95\% CI 1.9-5.6). A similar observation was made for the carriage of pneumococcal serotype content in PPV23 (2.3\% versus 4.1\%; PR 1.8, 95\% CI 1.2-2.7) and in PCV10 (0.6\% versus $1.6 \%$; PR2.6, 95\% CI 1.2-5.3) [17]. The potential coverage of PCV10, PCV 13 and PPV23 vaccines were $19 \%, 38 \%$ and $54 \%$, respectively [17]. These data were also confirmed during the 2013 Hajj [18]. The carriage of pneumococcal vaccine serotype has also increased between pre- and post-Hajj for PCV13 (0.3 versus 3.1\%), PCV10 ( $0.2 \%$ versus $1.8 \%)$, PPV 23 ( $0.2 \%$ versus $3.4 \%$ ). The potential coverage of PCV10, PCV 13 and PPV23 was 19.1\%, 35.5\% and 40\%, respectively, which was similar to the previous study. In the Indian pilgrim study where no individual was vaccinated, a higher potential coverage of PCV10, PCV 13 and PPV23 was evaluated, accounting for $47 \%, 56 \%$ and $76 \%$ of positive samples, respectively during the Hajj 2016 [22].

Table 2

Pneumococcal vaccination rates in Hajj pilgrims.

\begin{tabular}{|c|c|c|c|c|}
\hline $\begin{array}{l}\text { Country of origin of } \\
\text { pilgrims }\end{array}$ & $\begin{array}{l}\text { Year of } \\
\text { pilgrimage }\end{array}$ & $\begin{array}{l}\text { Prevalence of pneumococcal vaccination } \\
(\%)\end{array}$ & $\begin{array}{l}\text { Prevalence of pneumococcal vaccination (\%) in at-risk } \\
\text { patient }^{\mathrm{a}}\end{array}$ & References \\
\hline Australia & 2011 & 28.5 & 30.6 & [27] \\
\hline Australia & 2012 & 28.7 & 45.3 & [27] \\
\hline Australia & 2013 & 14.2 & 29 & [27] \\
\hline Australia & 2014 & 27.5 & $\mathrm{NA}^{\mathrm{b}}$ & [24] \\
\hline France & 2009 & 31.4 & $N A^{b}$ & [44] \\
\hline France & 2010 & 1.7 & 2.2 & [45] \\
\hline France & 2012 & 35.9 & 47.8 & [20] \\
\hline France & 2013 & 51.2 & $N A^{b}$ & [19] \\
\hline India & 2016 & 0 & 0 & [22] \\
\hline Iran & 2004 & 2.5 & $N A^{b}$ & [46] \\
\hline Iran & 2005 & 8.9 & $\mathrm{NA}^{\mathrm{b}}$ & [46] \\
\hline UK & 2005 & 5 & 15 & [14] \\
\hline Malaysia & 2013 & 79.3 & $N A^{b}$ & [23] \\
\hline Multinational cohort & 2013 & 4.4 & $\begin{array}{l}1.5 \% \text { in aged } \geq 65 \text { years } \\
27.3 \% \text { among diabetics }\end{array}$ & [47] \\
\hline Multinational cohort & 2013 & 1.4 & & [18] \\
\hline Multinational cohort & 2013 & 1.2 & $N A^{b}$ & [21] \\
\hline Multinational cohort & 2011-2012 & 11.3 & $\mathrm{NA}^{\mathrm{b}}$ & [17] \\
\hline
\end{tabular}

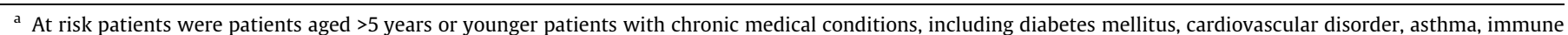
deficiency, chronic respiratory disease.

b NA: data not available. 


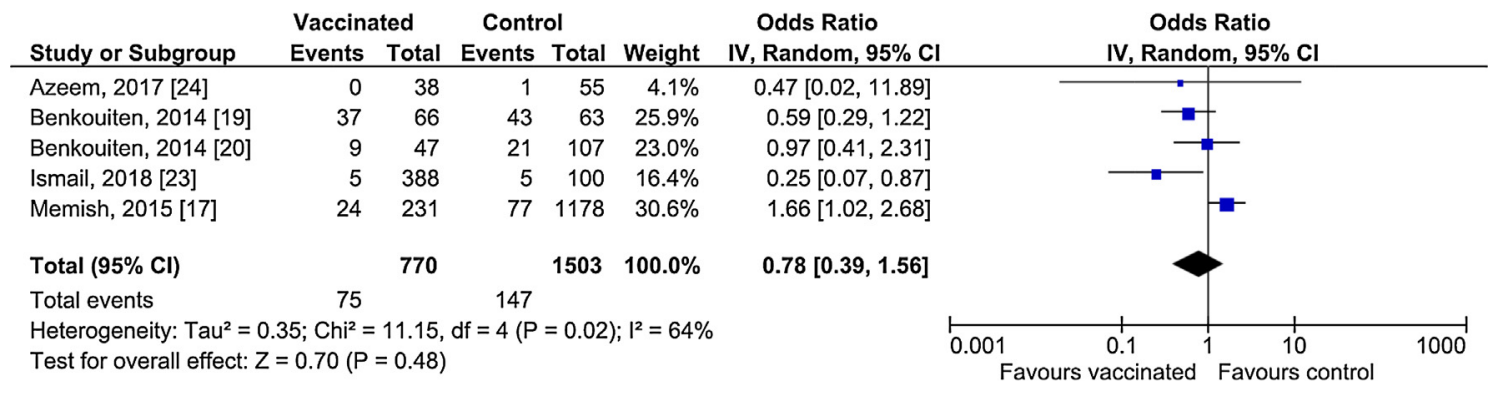

Fig. 3. The effect of pneumococcal vaccine on post-Hajj carriage of Streptococcus pneumoniae in pilgrims. Meta-analysis of five studies.

\section{Discussion}

All studies evaluated in this review support the fact that the overcrowding and mixing of populations increase pneumococcal carriage among pilgrims during the Hajj. Pneumococcal acquisition appears to be rapid after the arrival of pilgrims in Saudi Arabia, and no correlation was found between the rate of pneumococcal carriage and the duration of the Hajj stay [17]. No significant difference was found between the prevalence of $S$. pneumoniae in subjects tested at $<10$ days after their arrival (7.8\%), tested between 11 and 20 days (8.2\%) or more than 20 days (6.4\%) [17]. Several factors seemed to influence the carriage of $S$. pneumoniae during the Hajj, including advanced age [17,21], Hajj dates [17,19] and the geographical origin of pilgrims [17,21]. For example, Memish et al. did not find a significant change in the pneumococcal carriage among Indian pilgrims sampled before and after the pilgrimage, whereas the acquisition rate in Indonesian pilgrims was high (6.8\% versus $6.1 \%, p=0,70$, and $1.2 \%$ versus $8.3 \%$, respectively, $\mathrm{p}<0.0001$ ) [17]. The carriage of antibiotic-resistant $S$. pneumoniae increases during the Hajj, but does not appear to be linked to selfantibiotic use, which suggests frequent circulation and transmission of these strains [17]. High antibiotic consumption during the pilgrimages may increase selective pressure. Several serotypes were found to be circulating in the Hajj, including serotype 3 and $19 \mathrm{~F}$, which were the most common. However, isolated serotypes were not all covered by vaccine. The potential coverage of the PCV10, PCV 13 and PPV23 were around 20\%, 35\% and 50\%, respectively. These data were confirmed using Multilocus Sequence Typing, which showed that several clones of S. pneumoniae were present at the Hajj [17]. The most common clones included ST 700 and ST 9220, but no single invasive clonal expansion was identified. Increased carriage and serotype mixing following the Hajj may have an impact on the epidemiology of the disease in the countries of origin of the pilgrims, notably through the introduction of new serotypes and serotype replacement especially in countries that have introduced pneumococcal vaccination in their childhood vaccination programs.

The prevalence of nasopharyngeal carriage of $S$. pneumoniae varied according to the study and according to the Hajj season. Moreover, results from these studies cannot be extrapolated to all pilgrims from all countries, as only a small fraction of the over 2 million Hajj pilgrims have been investigated.

Culture remains the gold standard for pneumococcal detection. In the previous studies using culture, S. pneumoniae identification seems to be reliable; several phenotypic tests were used and molecular identification was performed in case of doubt $[17,18]$. However, the major limitation of some studies is the lack of data about antibiotic use among pilgrims during the stay, which certainly underestimates $S$. pneumoniae carriage, especially as pneumococci were evaluated by culture $[17,18]$. Overall, the prevalence of pneumococcal carriage was constantly lower when assessed by culture than when using qPCR. As an example, a 3 fold increase of pneumococcal detection in the nasopharynx was found using qPCR (19\%) compared to culture (6.5\%) in Indian pilgrims prior to the Hajj 2016 [22]. A similar pattern was observed postHajj; however, $45 \%$ of pilgrims received antibiotherapy during the Hajj. On other hand, some qPCR systems may lack specificity for pneumococcal detection. In fact, the qPCR system targeting the lytA gene of S. pneumoniae used by Benkouiten et al. $[19,20]$ and Memish et al. [21] also amplified S. pseudopneumoniae; however, the prevalence of $S$. pseudopneumoniae in the respiratory tract is low [28-30]. S. pseudopneumoniae was found in 1 to $12 \%$ of patients with respiratory tract infections, but was found more frequently in sputum than in nasopharyngeal samples [31]. Of $61 \mathrm{~S}$. pseudopneumoniae strains isolated from humans, 32 were isolated from sputum, 17 from bronchial aspirates, 4 from bronchoalveolar lavages, 1 from a nasal swab, 1 from a pharyngeal swab and 6 from other samples in one study [31].

The assessment of $S$. pneumoniae carriage is dependent on many factors, including the type of samples, their storage and laboratory techniques which may bias the results. In 2003 and 2013, the Pneumococcal Carriage Working Group from the World Health Organization (WHO) published recommendations to standardize the detection of bacteria in the upper respiratory tract [32]. In summary, for adults, both nasal and oropharyngeal samples are recommended to increase the sensitivity of pneumococcal detection [32]. If only one specimen can be collected, it is better to collect a nasopharyngeal sample than oropharyngeal specimens. Few data exists comparing sampling methods in adults, and they have shown discordant results. Some studies have shown a higher rate of nasal pneumococcus [33,34], but others have reported the superiority of oropharyngeal samples [35]. However, these recommendations are based mainly on culture detection of pneumococcus; further studies testing QPCR in nasal versus pharyngeal specimens are needed to establish if these recommendations can be applied to molecular detection. Nylon and Dacron swabs are suitable for culture-based methods and are preferred for molecular analysis, because they are less likely to inhibit DNA amplification. One milliliter of transport medium skim-milk tryptone glucose glycerol (STGG) broth is required; the swab should be transported to the laboratory within $8 \mathrm{~h}$ under cold conditions and frozen at $-70^{\circ} \mathrm{C}$ minimum as soon as possible [32]. We propose here our recommendations for future $S$. pneumoniae carriage studies in Hajj pilgrims, with a minor modification of the previous WHO recommendations (Table 3 ).

A high proportion of pilgrims were treated with antibiotics during the Hajj, which possibly affects the detection of pneumococcus, especially if culture is used. The prevalence of $S$. pneumoniae was probably underestimated in the studies using only a culture approach, because the bacteria are no longer viable after effective antibiotic treatment. This is less of a problem with PCR that detects bacterial DNA which is able to persist after efficient antibiotic treatment. DNA from Streptococcus spp. seems to be particularly persistent in clinical samples compared to DNA from others bacte- 
Table 3

Recommendations for future Streptococcus pneumoniae carriage studies in Hajj pilgrims.

\begin{tabular}{|c|c|}
\hline 1- Study design & $\begin{array}{l}\text { Longitudinal cohort design with paired samples } \\
\text { before and after the pilgrimage }\end{array}$ \\
\hline 2- Sampling & $\begin{array}{l}\text { Nasopharyngeal sample for culture-based methods } \\
\text { Nasopharyngeal, pharyngeal or nasal samples }{ }^{\text {a }} \text { for } \\
\text { qPCR }\end{array}$ \\
\hline $\begin{array}{l}\text { 3- Clinical } \\
\text { information } \\
\text { required }\end{array}$ & $\begin{array}{l}\text { Recording pneumococcal vaccination status and the } \\
\text { use of antibiotics }\end{array}$ \\
\hline 4- Technique & $\begin{array}{l}\text { qPCR is preferable for the screening of } S \text {. pneumoniae } \\
\text { carriage } \\
\text { Specific primer and probes lytA-CDC are } \\
\text { recommended } \\
\text { Culture is necessary for studying serotypes and } \\
\text { antibiotic susceptibility }\end{array}$ \\
\hline $\begin{array}{l}\text { 5-Transport and } \\
\text { storage }\end{array}$ & $\begin{array}{l}\text { Medium transport skim-milk tryptone glucose } \\
\text { glycerol (STGG) and transport to the laboratory within } \\
8 \mathrm{~h} \text { in cold condition }\end{array}$ \\
\hline 6-Storage & Frozen at $-70^{\circ} \mathrm{C}$ minimum \\
\hline
\end{tabular}

a Further studies testing qPCR in nasal versus pharyngeal specimens are needed to establish the recommendations.

rial species despite appropriate antibiotherapy [36,37]. As an example, DNA can persist for as long as 7 years after the infectious episode in a cardiac valve in a patient with endocarditis. Consequently, qPCR is probably the best tool to assess the carriage of pneumococcus in the Hajj pilgrims, but the disadvantages are that qPCR does not distinguish between living and dead microorganisms and does not allow assessing antibiotic susceptibility. Moreover, the most significant advantages of qPCR are the lower limit of detection compared to culture, notably in patients receiving antibiotherapy before sampling and a detailed quantification of pneumococci in the samples. Ganaie et al., found a clear difference of the number of DNA copy in patients presenting respiratory symptoms (mean 312 copie/ $\mu \mathrm{l}$ ) versus asymptomatic people (mean 145 copie $/ \mu \mathrm{l}$ ) and a clear difference of the number of DNA copy between the pre-Hajj group (mean 264 copie/ $\mu \mathrm{l}$ ) and the post-Hajj group (mean 480 copie/ $\mu \mathrm{l}$ ) [22]. The risk of contamination of the sample is low, especially when strict validated protocols with positive and negative controls are used.

However, misidentifications have been reported between $S$. pneumoniae and other viridans group streptococci, either by phenotypic identification, mass spectrometry (MALDI-TOF MS) identification or by PCR [38]. In fact, some qPCR systems also amplified $S$. pneumoniae-related bacteria, particularly S. pseudopneumoniae [38]. This is especially critical in non-sterile respiratory samples such as sputum, pharyngeal or nasal specimens. The usual targets used for specific S. pneumoniae qPCR are lytA, ply, Spn9802 and $p s a A$ genes. Most qPCR systems targeting lytA and psaA genes were specific for $S$. pneumoniae, although the previously popular PCR gene target ply has been found to be nonspecific [38,39]. The lytA-CDC system presents a high specificity for S. pneumoniae compared to other qPCR systems and clearly discriminates $S$. pneumoniae-related bacteria including $S$. pseudopneumoniae from $S$. pneumoniae $[38,40]$. This system is strongly recommended by the Pneumococcal Carriage Working Group from WHO [32].

Reducing pneumococcal disease and carriage in Hajj pilgrims involves a multi-pronged prevention approach, including vaccine [26]. Consistent local or national official recommendations on the use of pneumococcal vaccine for Hajj pilgrims are lacking $[14,26]$. Recommendations exist only for high risk individuals, and considerable variation exists between countries [14,26]. The recent recommendations of the Saudi Thoracic Society (STS) for pneumococcal vaccination before the Hajj season are to vaccinate all persons $\geq 50$ years with combined PCV13 and PPV23 vaccination [41]. A combination of these 2 vaccines was proposed to extend the spectrum of protections to a higher number of pneumococcal serotypes. Moreover, studies showed strong evidence of protective efficacy of PPV23 against IPD but its effect to prevent S. pneumoniae CAP is uncertain and no significant effect was found on nasopharyngeal carriage [42]. In contrast, PCV13 showed an efficient protection against pneumococcal bacteremic and nonbacteremic CAP, invasive pneumococcal disease and pneumococcal carriage $[42,43]$.

However, for those planning to be vaccinated immediately before the Hajj, it is recommended to administer only one dose of PPV23. It is recommended to administer a single PPV23 dose at least 3 weeks before the beginning of pilgrimage to immunocompetent persons aged less than 50 years with risk factors. The STS does not recommend pneumococcal vaccine routinely to healthy persons aged $<50$ years because of the lack of evidence of benefit-risk ratio and the lack of data about epidemiology of pneumococcal disease and pneumococcal serotype circulating during Hajj. However, the vaccine clearly elicits an immune response in this population. Approximately one third of pilgrims have risk factors for pneumococcal disease, with age and comorbidities [26]. However, the WHO and CDC recommend pneumococcal vaccine for Hajj pilgrims, but only for those aged $\geq 65$ years and for younger pilgrims with comorbidities [14].

The prevalence of vaccinated pilgrims has tended to increase in recent years, but still remains low in numerous countries, even in at-risk individuals [26]. Vaccination rates in at risk-French pilgrims prior inclusion were very low ( $<3 \%)$, comparing to overall French population of similar age range with vaccination rate varying $14.2-21.1 \%$ [48]. Following inclusion, however vaccination coverage increased to $31.4-51.2 \%$. Vaccination rates in at riskAustralian pilgrims after inclusion (14.2-28.7\%) were lower than in overall Australian population of similar age range with vaccination rate varying 50.3-72.8\% [49]. Continuing medical and health education is necessary to improve the vaccination rate. To date, the effectiveness of the PPV23 vaccine on pneumococcal carriage during the pilgrimage has not been proven, but few studies have been done, and most of them included a low number of patients. Further studies with a large number of patients and collection of accurate data on their vaccination status are needed to more precisely assess the effectiveness of pneumococcal vaccination with PPV23 or PCV on carriage during the pilgrimage.

\section{Conclusion}

All the studies analyzed in this review showed an increased carriage of pneumococci in post-Hajj pilgrims compared to pre-Hajj pilgrims, including vaccine serotypes. However, the distribution of $S$. pneumoniae serotypes during the Hajj should be more precisely characterized in order to provide reliable data on which to base recommendations for pneumococcal vaccination in Hajj pilgrims.

Further studies are needed to investigate the possible relationships between carriage, disease and vaccine efficacy during the pilgrimage. We recommend a longitudinal cohort design with paired samples before and at the end of the pilgrimage. Culture and qPCR are complementary for surveying the density and duration of pneumococcal carriage episodes. qPCR is preferable for the screening of pneumococcal carriage because of its high sensitivity, ease, and usability in large scale studies, but culture techniques are necessary for investigating antibiotic susceptibility and serotypes.

\section{Conflict of interest}

The authors report no conflict of interest. 


\section{References}

[1] Memish ZA, Zumla A, Alhakeem RF, Assiri A, Turkestani A, Al Harby KD, et al. Hajj: infectious disease surveillance and control. Lancet 2014;383:2073-82.

[2] Al-Tawfiq JA, Gautret P, Benkouiten S, Memish ZA. Mass gatherings and the spread of respiratory infections. Lessons from the Hajj. Ann Am Thorac Soc 2016;13:759-65.

[3] AlBarrak A, Alotaibi B, Yassin Y, Mushi A, Maashi F, Seedahmed Y, et al. Proportion of adult community-acquired pneumonia cases attributable to Streptococcus pneumoniae among Hajj pilgrims in 2016. Int J Infect Dis 2018;69:68-74.

[4] Shirah BH, Zafar SH, Alferaidi OA, Sabir AMM. Mass gathering medicine (Hajj Pilgrimage in Saudi Arabia): the clinical pattern of pneumonia among pilgrims during Hajj. J Infect Public Health 2017;10:277-86.

[5] Mandourah Y, Al-Radi A, Ocheltree AH, Ocheltree SR, Fowler RA. Clinical and temporal patterns of severe pneumonia causing critical illness during Hajj. BMC Infect Dis 2012;12:117.

[6] Johnson HL, Deloria-Knoll M, Levine OS, Stoszek SK, Freimanis Hance L, Reithinger R, et al. Systematic evaluation of serotypes causing invasive pneumococcal disease among children under five: the pneumococcal global serotype project. PLoS Med 2010;7.

[7] Bogaert D, De GR, Hermans PW. Streptococcus pneumoniae colonisation: the key to pneumococcal disease. Lancet Infect Dis 2004;4:144-54.

[8] Cremers AJ, Zomer AL, Gritzfeld JF, Ferwerda G, van Hijum SA, Ferreira DM, et al. The adult nasopharyngeal microbiome as a determinant of pneumococcal acquisition. Microbiome 2014;2:44.

[9] van Deursen AM, van den Bergh MR, Sanders EA. Carriage of Streptococcus pneumoniae in asymptomatic, community-dwelling elderly in the Netherlands. Vaccine 2016;34:4-6.

[10] Bosch AA, Van Houten MA, Bruin JP, Wijmenga-Monsuur AJ, Trzciński K, Bogaert D, et al. Nasopharyngeal carriage of Streptococcus pneumoniae and other bacteria in the 7th year after implementation of the pneumococcal conjugate vaccine in the Netherlands. Vaccine 2016;34:531-9.

[11] Simell B, Auranen K, Kayhty H, Goldblatt D, Dagan R, O'Brien KL. The fundamental link between pneumococcal carriage and disease. Exp Rev Vacc 2012;11:841-55.

[12] Flamaing J, Peetermans WE, Vandeven J, Verhaegen J. Pneumococcal colonization in older persons in a nonoutbreak setting. J Am Geriatr Soc 2010;58:396-8.

[13] Al-Tawfiq JA, Memish ZA. Prevention of pneumococcal infections during mass gathering. Hum Vaccin Immunother 2016:12:326-30.

[14] Ridda I, King C, Rashid H. Pneumococcal infections at Hajj: current knowledge gaps. Infect Disord Drug Targets 2014;14:177-84.

[15] Al-Tawfiq JA, Zumla A, Memish ZA. Respiratory tract infections during the annual Hajj: potential risks and mitigation strategies. Curr Opin Pulm Med 2013;19:192-7.

[16] Gautret P, Benkouiten S, Al-Tawfiq JA, Memish ZA. Hajj-associated viral respiratory infections: a systematic review. Travel Med Infect Dis 2016;14:92-109.

[17] Memish ZA, Assiri A, Almasri M, Alhakeem RF, Turkestani A, Al Rabeeah AA, et al. Impact of the Hajj on pneumococcal transmission. Clin Microbiol Infect 2015;21:77-8.

[18] Memish ZA, Al-Tawfiq JA, Almasri M, Akkad N, Yezli S, Turkestani A, et al. A cohort study of the impact and acquisition of naspharyngeal carriage of Streptococcus pneumoniae during the Hajj. Travel Med Infect Dis 2016;14:242-7.

[19] Benkouiten S, Charrel R, Belhouchat K, Drali T, Nougairede A, Salez N, et al. Respiratory viruses and bacteria among pilgrims during the 2013 Hajj. Emerg Infect Dis 2014:20:1821-7.

[20] Benkouiten S, Gautret P, Belhouchat K, Drali T, Salez N, Memish ZA, et al. Acquisition of Streptococcus pneumoniae carriage in pilgrims during the 2012 Hajj. Clin Infect Dis 2014;58:e106-9.

[21] Memish ZA, Assiri A, Turkestani A, Yezli S, Al Masri M, Charrel R, et al. Mass gathering and globalization of respiratory pathogens during the 2013 Hajj. Clin Microbiol Infect 2015;21:571-8.

[22] Ganaie F, Nagaraj G, Govindan V, Basha R, Hussain M, Ashraf N, et al. Impact of Hajj on the S. pneumoniae carriage among Indian pilgrims during 2016- a longitudinal molecular surveillance study. Travel Med Infect Dis 2018;23:64-71.

[23] Ismail N, Zainuddin NA, Deris Z, Rahman ZA, Mohamed Z, Harun A, et al. Streptococcus pneumoniae acquisition among vaccinated Malaysian hajj pilgrims and its associated factors. J Microbiol Infect Diseases 2018;7:56-62.

[24] Azeem MI, Tashani M, Badahdah AM, Heron L, Pederson K, Jeoffreys N, et al. Surveillance of Australian Hajj pilgrims for carriage of potentially pathogenic bacteria: data from two pilot studies. World J Clin Cases 2017;5:102-11.

[25] Licensure of a 13-valent pneumococcal conjugate vaccine (PCV13) and recommendations for use among children - Advisory Committee on Immunization Practices (ACIP), 2010. MMWR Morb Mortal Wkly Rep 2010;59:258-61.
[26] Rashid H, Abdul Muttalif AR, Mohamed Dahlan ZB, Djauzi S, Iqbal Z, Karim HM, et al. The potential for pneumococcal vaccination in Hajj pilgrims: expert opinion. Travel Med Infect Dis 2013;11:288-94.

[27] Tashani M, Barasheed O, Azeem M, Alfelali M, Badahdad AM, Bokhary H, et al. Pneumococcal vaccine uptake among Australian Hajj Pilgrims in 2011-13. Infect Disord Drug Targets 2014;14:117-24.

[28] Harf-Monteil C, Granello C, Le BC, Monteil H, Riegel P. Incidence and pathogenic effect of Streptococcus pseudopneumoniae. J Clin Microbiol 2006;44:2240-1.

[29] Laurens C, Michon AL, Marchandin H, Bayette J, Didelot MN, Jean-Pierre H. Clinical and antimicrobial susceptibility data of 140 Streptococcus pseudopneumoniae isolates in France. Antimicrob Agents Chemother 2012;56:4504-7.

[30] Mohammadi JS, Dhanashree B. Streptococcus pseudopneumoniae: an emerging respiratory tract pathogen. Indian J Med Res 2012;136:877-80.

[31] Rolo D, Simoes S, Domenech A, Fenoll A, Liñares J, de Lencastre H, et al. Disease isolates of Streptococcus pseudopneumoniae and non-typeable S. pneumoniae presumptively identified as atypical S. pneumoniae in Spain. PLoS ONE 2013;8: e57047.

[32] Satzke C, Turner P, Virolainen-Julkunen A, Adrian PV, Antonio M, Hare KM, et al. Standard method for detecting upper respiratory carriage of Streptococcus pneumoniae: updated recommendations from the World Health Organization Pneumococcal Carriage Working Group. Vaccine 2013;32:165-79.

[33] Levine H, Zarka S, Dagan R, Sela T, Rozhavski V, Cohen DI, et al. Transmission of Streptococcus pneumoniae in adults may occur through saliva. Epidemiol Infect 2012;140:561-5.

[34] Lieberman D, Shleyfer E, Castel H, Terry A, Harman-Boehm I, Delgado J, et al Nasopharyngeal versus oropharyngeal sampling for isolation of potential respiratory pathogens in adults. J Clin Microbiol 2006;44:525-8.

[35] Principi N, Terranova L, Zampiero A, Manzoni F, Senatore L, Rios WP, et al Oropharyngeal and nasopharyngeal sampling for the detection of adolescent Streptococcus pneumoniae carriers. J Med Microbiol 2014;63:393-8.

[36] Branger S, Casalta JP, Habib G, Collard F, Raoult D. Streptococcus pneumoniae endocarditis: persistence of DNA on heart valve material 7 years after infectious episode. J Clin Microbiol 2003;41:4435-7.

[37] Casalta JP, Thuny F, Fournier PE, Lepidi H, Habib G, Grisoli D, et al. DNA persistence and relapses questions on the treatment strategies of Enterococcus infections of prosthetic valves. PLoS ONE 2012;7:e53335.

[38] Carvalho MG, Tondella ML, McCaustland K, Weidlich L, McGee L, Mayer LW, et al. Evaluation and improvement of real-time PCR assays targeting lytA, ply, and psaA genes for detection of pneumococcal DNA. J Clin Microbiol 2007;45:2460-6.

[39] Abdeldaim G, Herrmann B, Korsgaard J, Olcen P, Blomberg J, Stralin K. Is quantitative PCR for the pneumolysin (ply) gene useful for detection of pneumococcal lower respiratory tract infection? Clin Microbiol Infect 2009:15:565-70.

[40] Stralin K, Herrmann B, Abdeldaim G, Olcen P, Holmberg H, Molling P. Comparison of sputum and nasopharyngeal aspirate samples and of the PCR gene targets lytA and Spn9802 for quantitative PCR for rapid detection of pneumococcal pneumonia. J Clin Microbiol 2014;52:83-9.

[41] Alharbi NS, Al-Barrak AM, Al-Moamary MS, Zeitouni MO, Idrees MM, AlGhobain MO, et al. The Saudi Thoracic Society pneumococcal vaccination guidelines-2016. Ann Thorac Med 2016;11:93-102.

[42] Moberley S, Holden J, Tatham DP, Andrews RM. Vaccines for preventing pneumococcal infection in adults. Cochrane Database Syst Rev 2013;1: CD000422.

[43] Bonten MJ, Huijts SM, Bolkenbaas M, Webber C, Patterson S, Gault S, et al Polysaccharide conjugate vaccine against pneumococcal pneumonia in adults. N Engl J Med 2015;372:1114-25.

[44] Gautret P, Vu HV, Sani S, Doutchi M, Parola P, Brouqui P. Protective measures against acute respiratory symptoms in French pilgrims participating in the Hajj of 2009. J Travel Med 2011;18:53-5.

[45] Gautret P, Bauge M, Simon F, Benkouiten S, Parola P, Brouqui P. Pneumococcal vaccination and Hajj. Int J Infect Dis 2011;15:e730.

[46] Meysamie A, Ardakani HZ, Razavi SM, Doroodi T. Comparison of mortality and morbidity rates among Iranian pilgrims in Hajj 2004 and 2005. Saudi Med J 2006;27:1049-53.

[47] Memish ZA, Assiri A, Almasri M, Alhakeem RF, Turkestani A, Al Rabeeah AA et al. Prevalence of MERS-CoV nasal carriage and compliance with the Saudi health recommendations among pilgrims attending the 2013 Hajj. J Infect Dis 2014;210:1067-72.

[48] Goulenok T. Pneumococcal vaccine in adults: how to improve the vaccine rate? J Anti-inf 2014;16:89-98.

[49] Dyda A, Karki S, Hayen A, MacIntyre CR, Menzies R, Banks E, et al. Influenza and pneumococcal vaccination in Australian adults: a systematic review of coverage and factors associated with uptake. BMC Infect Dis. 2016;16(1):515. 